\title{
Basal core promoter mutation is associated with progression to cirrhosis rather than hepatocellular carcinoma in chronic hepatitis B virus infection
}

\author{
C-M Chu*, , C-C Lin', Y-C Chen', W-J Jeng', S-M Lin' and Y-F Liaw' \\ 'Liver Research Unit, Department of Gastroenterology and Hepatology, Chang Gung Memorial Hospital, Chang Gung University College of Medicine, \\ 199, Tung Hwa North Road, Taipei 1059 I, Taiwan
}

BACKGROUND: As most cases of hepatitis B virus (HBV)-related hepatocellular carcinoma (HCC) have concurrent cirrhosis, viral factors identified to be associated with HCC might be related to cirrhosis rather than HCC.

METHODS: Hepatitis B virus DNA levels, genotypes and precore/basal core promoter (BCP) mutants were compared between cirrhotic HCC and non-cirrhotic HCC patients. Age- and sex-matched case-control studies were performed to identify the risk factors.

RESULTS: Hepatitis B virus DNA levels showed no significant difference betwen non-cirrhotic HCC patients $(n=20)$ and cirrhotic HCC patients $(n=140)$ or $1: 3$ age- and sex-matched cirrhotic HCC patients $(n=60)$, but genotype C and BCP mutant were significantly more prevalent in the latter than in the former. In multiple logistic regression, BCP mutant but not genoype $\mathrm{C}$ correlated significantly with the presence of cirrhosis in HCC patients. Compared with inactive carriers $(n=60)$, non-cirrhotic HCC patients $(n=20)$ had significantly higher HBV DNA levels but no difference in HBV genotypes and precore/BCP mutants. Furthermore, HBV DNA levels, the distribution of HBV genotypes and the prevalence of precore/BCP mutants all failed to show any significant difference between cirrhotic HCC patients $(n=60)$ and cirrhotic patients without HCC $(n=60)$.

CONCLUSION: Basal core promoter mutant is associated with progression to cirrhosis rather than HCC in chronic HBV infection. British Journal of Cancer (2012) I 07, 2010-2015. doi:I0.1038/bjc.2012.474 www.bjcancer.com

Published online 18 October 2012

(c) 2012 Cancer Research UK

Keywords: basal core promoter mutant; Cirrhosis; HBV DNA levels; HBV genotypes; hepatocellular carcinoma; precore mutant

Hepatocellular carcinoma (HCC) is one of the most common malignant tumours worldwide. Infection with hepatitis $B$ virus (HBV) has, by far, the strongest association with HCC of any aetiological agents (Liaw and $\mathrm{Chu}, 2009$ ). Viral factors such as HBV genotypes, viral mutants and viral load may have an utmost important role in the pathogenesis of HBV-related HCC (Chan, 2011). The most prevalent HBV genotypes in Asia are genotypes B and C (Kao, 2002; Chu and Liaw, 2005). Several crosssectional or longitudinal studies reported a higher risk of HCC among genotype $\mathrm{C}$ infected patients (Kao, et al, 2000; Fujie, et al, 2001; Yu et al, 2005). Virologically, genotype C HBV has a higher frequency of basal core promoter (BCP) mutation than genotype B HBV (Lindh et al, 1999; Orito et al, 2001). The frequency of BCP mutation increases with progression of liver disease (Takahashi et al, 1995; Fang et al, 2002; Kao et al, 2003; Chen et al, 2005; Lin et al, 2005). In addition, a recent prospective longitudinal study from Taiwan revealed that the risk for cirrhosis and HCC increased with increasing HBV DNA levels in a dose-response relationship and that

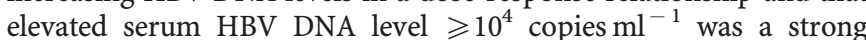
predictor of cirrhosis and HCC (Chen et al, 2006; Iloeje et al, 2006).

\footnotetext{
*Correspondence: Professor C-M Chu;

E-mail: chiamingchu@yahoo.com.tw

Received 2 July 2012; revised 24 September 2012; accepted 24 September 2012; published online 18 October 2012
}

The independent and interactive effects of individual viral factor on the development of HCC have been studied by multivariate analysis but the results are still inconclusive. In several casecontrol studies, HBV DNA levels $\geqslant 10^{4}$ copies $\mathrm{ml}^{-1}$ (Yuen et al, 2008) or $\geqslant 10^{5}$ copies $\mathrm{ml}^{-1}$ (Liu et al, 2006) and BCP T1762/A1764 mutant (Liu et al, 2006; Tong et al, 2007; Yuen et al, 2008), but not genotype C (Liu et al, 2006; Yuen et al, 2008) were independent risk factors for HCC development; precore A1896 mutant was independently associated was HCC development in some studies (Liu et al, 2006, Tong et al, 2007) but not in others (Yuen et al, 2008). The results of prospective longitudinal studies also were controversial. In one study from southern China, BCP T1762/ A1764 mutant was a significant aetiological factor for HCC (Fang et al, 2008), in another study from Hong Kong, genotype C, but not BCP T1762/A1764 mutant, increased the risk of HCC (Chan et al, 2004), and in the other study from Taiwan, HBV DNA level, genotype C and BCP T1762/A1764 mutant all were independent predictors for HCC, while precore A1896 mutant was significantly associated with low risk of HCC (Yang et al, 2008). The reasons for such remarkable discrepancies remain unclear. In a recent metaanalysis of 43 studies enroling 11582 patients with chronic HBV infection, BCP T1762T/A1764 mutant is the most common mutation that is statistically significantly associated with the development of HCC; the presence of BCP T1762/A1764 mutant is associated with an odds ratio of 3.79 for HCC development (Liu et al, 2009). 
The majority of paitients with HCC have concurrent liver cirrhosis. Unfortunately, most previous studies did not particularly categorise the HCC patients into cirrhotics and non-cirrhotics. Viral factors identified to be associated with HCC might be related to cirrhosis rather than HCC. In this study, we first compared the clinical and virological characteristics including HBV DNA levels, HBV genotypes, precore A 1896 and BCP T1762/A1764 mutants betwen cirrhotic and non-cirrhotic patients with HBV-related HCC. We then performed case-control studies by comparing the virological characteristics between non-cirrhotic patients with HCC and age- and sex-matched inactive carriers to identify factors significantly associated with HCC development in non-cirrhotic patients, and between cirrhotic patients with HCC and ageand sex-matched cirrhotic patients but without HCC to identify factors significantly associated with HCC development in cirrhotic patients. Meanwhile, we also performed a case-control study including cirrhotic patients without HCC and age- and sexmatched inactive carriers to identify viral factors responsible for progression to cirrhosis.

\section{MATERIALS AND METHODS}

This study was approved by the Institutional Review Board of Chang Gung Memorial Hospital at Taipei, and was carried out in accordance with the Helsinki Declaration of 1975.

\section{Patients and controls}

Between 2007 and 2008, 160 consecutive patients with newly diagnosed HBV-related HCC were recruited from our unit. All these patients were positive for hepatitis $\mathrm{B}$ surface antigen (HBsAg) but negative for antibodies against hepatitis $\mathrm{C}$ virus (anti-HCV) and antibody against hepatitis D virus (anti-HDV). Patients who had other concomitant diseases including alcoholic liver disease, autoimmune hepatitis, primary biliary cirrhosis, hemochromatosis and Wilson's disease were excluded. The diagnosis of HCC was based on histopathology (fine needle aspiration, core liver biopsy or surgical resection) or typical radiological features (hypervascularity on the arterial phase and washout during the venous phase in dynamic computed tomography or magnetic resonance imaging) (Bruix and Sherman, 2005). The radiological diagnosis of HCC for $1-2 \mathrm{~cm}$ tumour needed at least two dynamic imaging techniques showing typical features of HCC and only a single dynamic study showing the typical features of HCC was necessary to confirm the diagnosis of HCC for a tumour $>2 \mathrm{~cm}$. If the radiological appearances were not typical, the diagnosis of HCC was confirmed by histopathological examination. The diagnosis of cirrhosis was confirmed histologically or was based on clinical parameters and liver ultrasonographic findings (Lin et al, 1993).

Two groups of controls with no evidence of HCC based on clinical assessment and liver ultrasonographic findings were included during the same study period: (1) age- and sex-matched, hepatitis $\mathrm{B}$ e antigen ( $\mathrm{HBeAg}$ )-negative and antibody against $\mathrm{HBeAg}$ (anti-HBe)-positive inactive carriers with persistently normal ALT levels $\left(\leqslant 36 \mathrm{Ul}^{-1}\right)$ for more than 10 years, as previously reported (Chu et al, 2010), and (2) age- and sexmatched HBsAg-positive patients with cirrhosis. All these two controls also had no other concomitant diseases, including alcoholic liver disease, autoimmune hepatitis, primary biliary cirrhosis, hemochromatosis or Wilson's disease.

\section{Methods}

Hepatitis B surface antigen, $\mathrm{HBeAg}$, anti-HBe and anti-HDV were assayed using radioimmunoassay or enzyme immunoassay kits (Abbott Diagnostics, North Chicago, IL, USA). Anti-HCV was using a third-generation enzyme immunoassay (Abbott Diagnostics). Serum HBV DNA levels were assayed using the COBAS Amplicor HBV Monitor Test (Roche Diagnostics, Branchburg, NJ, USA; lower limit of detection 300 copies $\mathrm{ml}^{-1}$ ). The conversion in $\mathrm{IU} \mathrm{ml}^{-1}$ ( $1 \mathrm{IU}$ is equivalent to $5.26 \mathrm{HBV}$ DNA copies) was made according to the manufacturer's instructions. Hepatitis B virus genotypes were determined by using the PCRrestriction fragment length polymorphism of the surface gene of HBV, as previously described (Chu and Liaw, 2005), or by using a commercial genotype-specific probes assay (SMITEST HBV Genotyping Kit, Medical and Biological Laboratories Co., LTD, Nagoya, Japan) (Sugauchi et al, 2003). Precore A1896 mutant was detected by amplification-created restriction site method, as described before (Chu et al, 1996). BCP genes were amplified by PCR, and nucleotide sequences of the amplified products were directly determined by using an automatic sequencer.

\section{Statistical analyses}

Data were presented as mean \pm s.d., median (interquartile range) or number (\%). To compare characteristics between groups, either the $\chi^{2}$-test or Fisher's exact test was used to analyse categorical variables and the Student's $t$-test or Mann-Whitney $U$ nonparametric test was used to analyse continuous variables. Univariate and multivariate logistic regression analyses were performed to identify the factors that correlated with the development of cirrhosis or HCC. Variables with $P$ values $<0.1$ in the univariate models were tested in a multivariate setting. Significant associations identified in multivariate analysis were presented as odds ratio (95\% confidence interval). Statistical procedures were performed using the SPSS statistical software (version 13.0; SPSS, Chicago, IL, USA). $P$ values $<0.05$ were considered significant.

\section{RESULTS}

Of the 160 HCC patients, 140 had cirrhosis, based on pathological examination in 50 (18 by percutaneous liver biopsy before the detection of HCC and 32 during hepatic resection or liver transplantation), and on liver ultrasonographic findings in 90. Among 50 patients with pathology-verified cirrhosis, oesophageal or gastric varices was detected in $68.9 \%(22 / 32)$, splenomegaly by ultrasonography in $62 \%(31 / 50)$ and thrombocytopenia in $64 \%$ $(32 / 50)$. Totally, 38 patients $(76 \%)$ had at least one sign of portal hypertension. Among 90 patients with ultrasonographic diagnosis of cirrhosis, oesophageal or gastric varices was detected in $70.8 \%$ (51/72), splenomegaly by ultrasonography in $64.4 \%(58 / 90)$ and thrombocytopenia in $72.2 \%(65 / 90)$. Totally, 71 patients $(78.9 \%)$ had at least one sign of portal hypertension. The remaining 20 patients had non-cirrhotic liver, based on pathological examination during hepatic resection in 9 and on liver ultrasonographic findings in 11. All these 20 patients had normal spleen size by ultrasonography and normal platelet count and none of 12 patients who received esohagogastroduodenscopy examination had oesophageal or gastric varices.

\section{Comparison of clinical, demographic and virological characteristics between cirrhotic patients with HCC and non-cirrhotic patients with HCC}

The comparison of clinical, demographic and virological characteristics between cirrhotic patients with HCC and non-cirrhotic patients with HCC are summarised in Table 1.

Non-cirrhotic patients were significantly younger than cirrhotic patients. The frequency of HBeAg and levels of HBV DNA showed no significant difference between them. However, cirrhotic patients had significantly higher frequency of genotype $C$ and BCP T1762/A1764 mutant than non-cirrhotic patients. The same 
Table I Clinical and virological characteristics of HBV-related HCC: comparison between cirrhotic and non-cirrhotic patients

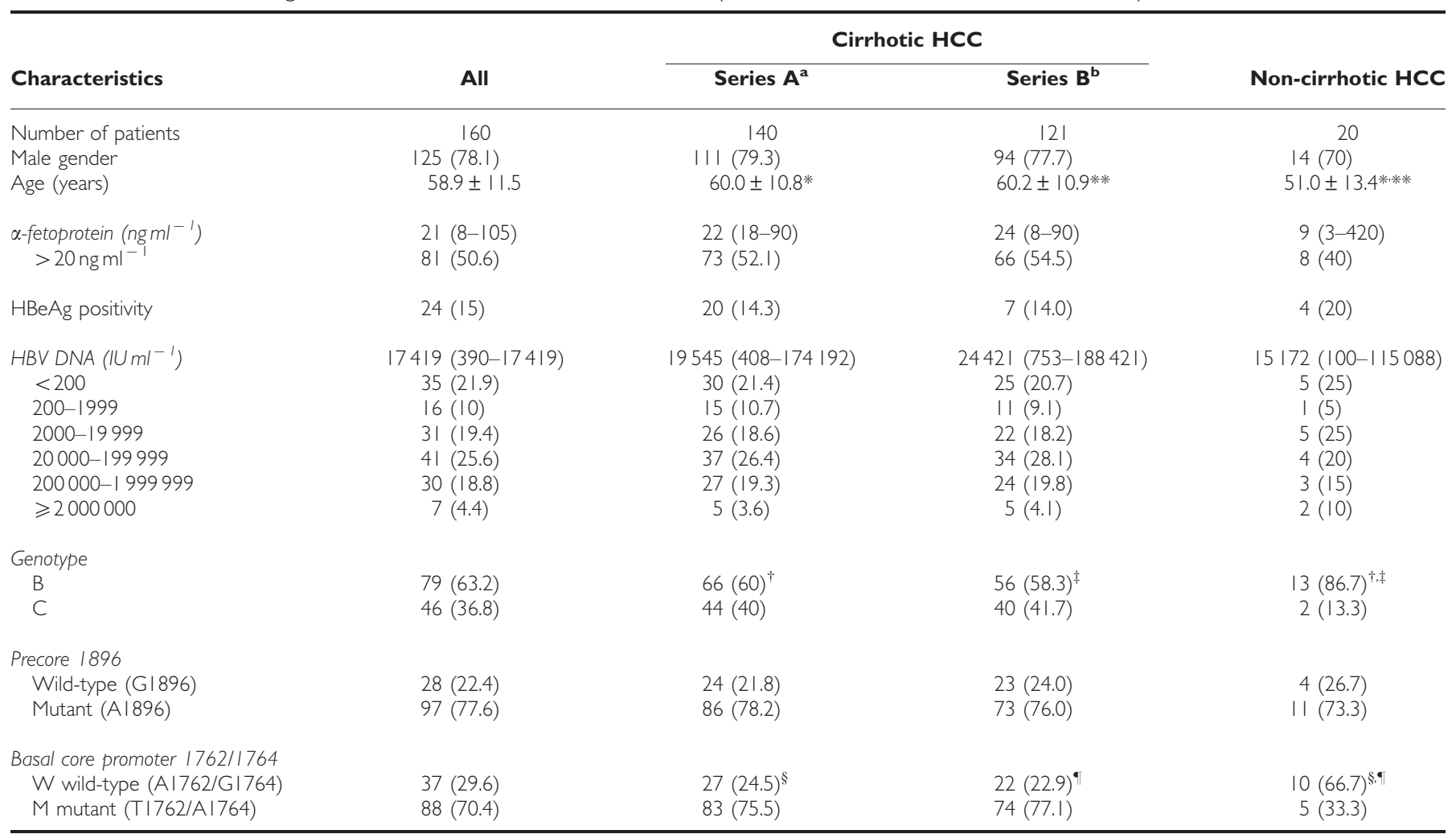

Abbreviations: HBV = hepatitis B virus; $\mathrm{HCC}=$ hepatocellular carcinoma; HBeAg = hepatitis B e antigen. Data are presented as $n$ (\%), mean \pm s.d. or median (interquartile range) ${ }^{*} P=0.008$, ${ }^{*} * P=0.008,{ }^{\dagger} P=0.044,{ }^{\ddagger} P=0.035{ }^{\circledR} P=0.0008,{ }^{\circledR} P=0.0005$. ${ }^{\circledR}$ Series A: including 50 patients with pathological diagnosis of cirrhosis and 90 with ultrasonographic diagnosis of cirrhosis. 'beries B: including 50 patients with pathological diagnosis of cirrhosis and 7 I with ultrasonograpic diagnosis of cirrhosis who had at least one sign of portal hypertension.

findings were present if patients in the cirrhotic group without histological confirmation and any sign of portal hypertension were excluded. The association of older age, genotype $\mathrm{C}$ and $\mathrm{BCP}$ T1762/A1764 mutant with cirrhosis in univariate analysis were then analysed by using multiple logistic regression analysis. As shown in Table 2, older age and BCP T1762/A1764 mutant, but not genotype $C(P=0.35)$, correlated significantly with the presence of cirrhosis in HCC patients.

As the non-cirrhotic patients were significantly younger than cirrhotic patients by a mean of 9 years (Table 1), further analysis was performed by comparing the virological characteristics between 20 non-cirrhotic patients with HCC and $1: 3$ age- and sex-matched cirrhotic patients with HCC. As shown in Table 3, the virological differences between them were essentially the same as those seen in Table 1.

Comparison of virological characteristics between noncirrhotic patients with HCC and age- and sex-matched inactive carriers

To identify viral factors associated with the development of HCC in non-cirrhotic patients, a case-control study was performed by including 20 non-cirrhotic patients with HCC and 1:3 age- and sex-matched inactive carriers. As shown in Table 3, non-cirrhotic patients with HCC had significantly higher frequency of $\mathrm{HBeAg}$ and higher levels of HBV DNA than inactive carriers. However, the distribution of HBV genotypes and the frequency of precore A1896 and BCP T1762/A1764 mutants all showed no significant difference between them. In multiple logistic regression, HBV DNA level $\geqslant 20000 \mathrm{IU} \mathrm{ml}^{-1}$, but not HBeAg $(P=0.97)$, was
Table 2 Association of older age and basal core promoter mutant with cirrhosis in patients with HCC: multiple logistic regression analysis

\begin{tabular}{lcc}
\hline Variables & Odds ratio (95\% Cl) & P-value \\
\hline Age (per year increase) & $1.07(1.01-1.12)$ & 0.015 \\
$\begin{array}{l}\text { Basal core promoter 1762/1764 } \\
\text { Wild-type (AI762/G 1764) } \\
\text { Mutant (TI762/AI 764) }\end{array}$ & $4.403(1.17-16.59)$ & \\
\hline
\end{tabular}

Abbreviations: $\mathrm{Cl}=$ confidence interval; $\mathrm{HBV}=$ hepatitis $\mathrm{B}$ virus; $\mathrm{HCC}=$ hepatocellular carcinoma.

significantly associated with HCC in non-cirrhotic patients (Table 4).

\section{Comparison of virological characteristics between cirrhotic patients with HCC and age-and sex-matched cirrhotic patients without $\mathrm{HCC}$}

To identify viral factors correlated with the development of HCC in cirrhotic patients, a case-control study was performed by including 60 cirrhotic patients with HCC and 60 age- and sexmatched cirrhotic patients without HCC. As shown in Table 3, virological characteristics including HBV DNA levels, the distribution of $\mathrm{HBV}$ genotypes and the prevalence of precore A1896 and BCP T1762/A1764 mutants all showed no significant difference between cirrhotic patients with and without HCC. 
Table 3 Comparison of virological characteristics among age- and sex-matched non-cirrhotic HCC, cirrhotic HCC, inactive carriers and cirrhotics with HCC

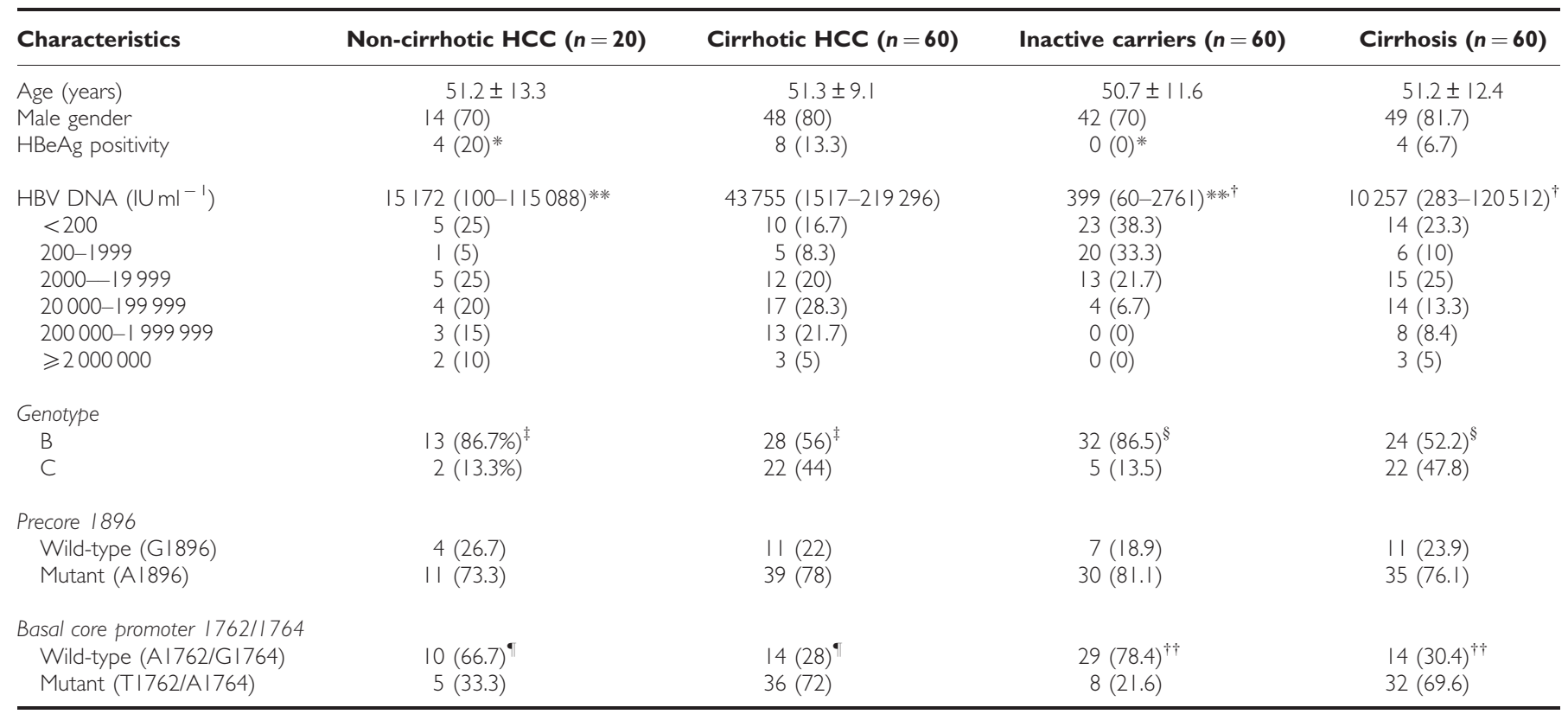

Abbreviations: $\mathrm{HBV}=$ hepatitis $\mathrm{B}$ virus; $\mathrm{HCC}=$ hepatocellular carcinoma; $\mathrm{HBeAg}=$ hepatitis $\mathrm{B}$ e antigen. Data are presented as $n$ (\%), mean \pm s.d. or median (interquartile range). ${ }^{*} P=0.003, * * P=0.004,{ }^{\dagger} P=0.004,{ }^{\ddagger} P=0.03,{ }^{\circledR} P=0.0009,{ }^{\circledR} P=0.0065,{ }^{\dagger \dagger} P<0.0001$.

Table 4 Association of HBV DNA levels with HCC in non-cirrhotic patients: multiple logistic regression analysis

\begin{tabular}{|c|c|c|}
\hline HBV DNA (IU ml $\left.{ }^{-1}\right)$ & Odds ratio $(95 \% \mathrm{Cl})$ & $P$ \\
\hline $\begin{array}{l}<2000 \\
2000-19999 \\
\geqslant 20000\end{array}$ & $\begin{array}{c}1 \\
2.21(0.54-9.03) \\
10.75(2.34-49.84)\end{array}$ & $\begin{array}{l}0.27 \\
0.0023\end{array}$ \\
\hline
\end{tabular}

\section{Comparison of virological features between cirrhotic patients and age- and sex-matched inactive carriers}

In the meanwhile, to identify viral factors involved in the pathogenesis of HBV-related cirrhosis, a case-control study was performed by including 60 cirrhotic patients without HCC and 60 sex- and age-matched inactive carriers. As shown in Table 3, the cirrhotic patients had significantly higher levels of HBV DNA, higher frequency of genotype C and BCP T1762/A1764 mutant, compared with inactive carriers. Multiple logistic regression analysis identified HBV DNA levels $\geqslant 20000 \mathrm{IU} \mathrm{ml}^{-1}$ and BCP T1762/A1764 mutant but not genotype C $(P=0.43)$ were independent predictors for progression to cirrhosis (Table 5).

\section{DISCUSSION}

Among $160 \mathrm{HBV}$-related HCC in this series, 20 were non-cirrhotic and the other 140 were cirrhotic. Only 9 and 50 patients, respectively, were verified to have non-cirrhotic and cirrhotic liver by pathological examination. A high-resolution real-time ultrasound was used to determine the presence or absence of cirrhosis in the remaining patients. This technique is somewhat limited with sensitivity and specificity in the $80 \%$ range (Lin et al, 1993). However, clinical signs of portal hypertension, such as oesophageal or gastric varices, splenomegaly or thrombocytopenia, were not seen in any patients with ultrasonographic diagnosis of
Table 5 Association of HBV DNA levels and basal core promoter mutant with cirrhosis: multiple logistic regression analysis

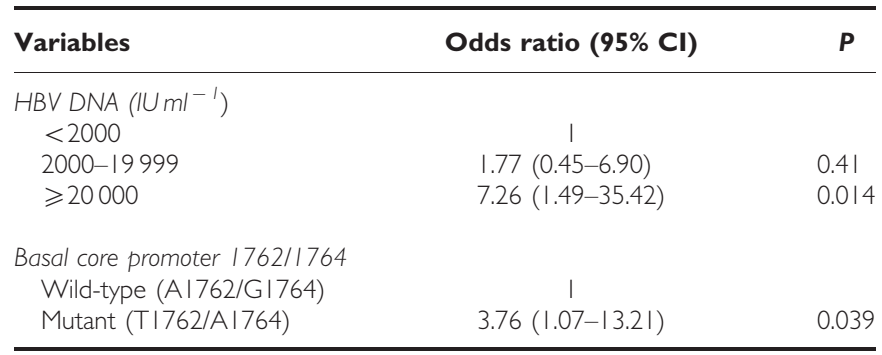

Abbreviations: $\mathrm{Cl}=$ confidence interval; $\mathrm{HBV}=$ hepatitis $\mathrm{B}$ virus.

non-cirrhotic liver but were evident in $\sim 70 \%$ of patients with ultrasonographic diagnosis of cirrhosis. These figures were similar to those observed in the pathology-verified patients.

In this investigation, we have shown that, among patients with HBV-related HCC, there was no significant difference in gender distribution, but the non-cirrhotic patients were significantly younger than the cirrhotic patients by a mean of about 10 years (Table 1). The frequency of HBeAg and levels of HBV DNA did not show significant difference between cirrhotic patients and noncirrhotic patients. However, the non-cirrhotic patients had significantly higher frequency of genotype B and lower frequency of BCP T1762/A1764 mutant than the cirrhotic patients (Table 1). The findings of younger age and higher frequency of genotype B in non-cirrhotic patients than cirrhotic patients in this series were consistent with the early observations reported by others from Taiwan (Kao et al, 2000). In a cross-sectional study, Kao et al (Kao et al, 2000) first reported that genotype B was associated with HCC in patients younger than 50 years (the majority of them were noncirrhotic) and genotype $\mathrm{C}$ was associated with HCC in patients older than 50 years (the majority of them were cirrhotic). The lower frequency of BCP T1762/A1764 mutant in non-cirrhotic patients in our series might be attributed to the lower frequency of genotype $\mathrm{C}$ in these patients, as genotype $\mathrm{C} \mathrm{HBV}$ has higher 
frequency of BCP mutant than genotype B HBV (Lindh et al, 1999; Orito et al, 2001). As the number of non-cirrhotic patients with HCC in this series was relatively small, further studies of a larger series of patients are needed to confirm these observations.

By using multiple logistic regression analysis, the present investigation showed that older age and BCP T1762/A1764 mutant but not genotype $\mathrm{C}$ independently correlated with the presence of cirrhosis in HCC patients (Table 2). These findings highly suggested that BCP T1762/A1764 mutant may have an important role in the pathogenesis of HBV-related cirrhosis.

Several previous case series also reported a higher frequency of BCP T1762/A1764 mutant in patients with cirrhosis than in inactive carriers or patients with chronic hepatitis (Takahashi et al, 1995; Fang et al, 2002; Kao et al, 2003; Chen et al, 2005; Lin et al, 2005). The present investigation is the first case-control study to identify viral factors significantly associated with progression to cirrhosis in chronic HBV infection. In this analysis, the inactive carriers had persistently normal ALT levels for at least 10 years and were presumed at minimal potential for progression of liver disease (Tai et al, 2009), and thus could be served as suitable controls. Moreover, the inactive carriers were age- and sexmatched for patients with cirrhosis. Both age and sex are important host factors in the pathogenesis of HBV-related cirrhosis (Liaw et al, 1988; Fattovich et al, 1991). Our results identified two factors significantly predictive for progression to cirrhosis (Table 5). Patients with HBV DNA levels $\geqslant 20000 \mathrm{IU} \mathrm{ml}^{-1}$ were approximately seven times more likely to have cirrhosis than those with levels $<2000 \mathrm{IU} \mathrm{ml}^{-1}$. Another factor predictive for progression to cirrhosis was the presence of BCP T1762/A1764 mutant, which was associated with about 4-fold increased risk of cirrhosis. Genotype $\mathrm{C}$ correlated with progression to cirrhosis in univariate analysis (Table 3), but it became nonsignificant in the multivariate analysis (Table 5). As genotype $\mathrm{C}$ HBV tends to have a high prevalence of BCP T1762/A1764 mutant (Lindh et al, 1999; Orito et al, 2001), the effect of BCP T1762/A1764 mutant on the development of cirrhosis might be strong enough to mask the effect of genotype C. Further prospective studies are needed to clarify the role of each viral factor in the progression of liver diseases. The frequency of precore A1896 mutant was high in patients with cirrhosis $(76 \%)$, but this figure was similar to that observed in inactive carriers $(81 \%)$, as shown in Table 3. These findings are in keeping with our previous observations that precore A1896 mutant is highly prevalent in patients with chronic HBV infection and does not seem to have an important role in the progression of liver disease in our area (Chu et al, 1996).

This investigation then analysed viral factors significantly associated with the development of HCC in non-cirrhotic patients by comparison of virological characteristics between non-cirrhotic patients with HCC and age- and sex-matched inactive carriers. As shown in Table 3, the frequency of HBeAg and levels of HBV DNA were significantly higher in non-cirrhotic patients with HCC than in inactive carriers, while HBV genotypes, precore A1896 and BCP T1762/A1764 mutants showed no significant difference between them. Multiple logistic regression analysis revealed that HBV DNA level was the only factor significantly correlated with HCC development in non-cirrhotic patients (Table 4). The results of this investigation argued against the role of genotype $\mathrm{C}$, precore A1896 or BCP T1762/A1764 mutant in the pathogenesis of HCC in non-cirrhotic patients.

\section{REFERENCES}

Bruix J, Sherman M (2005) Management of hepatocellular carcinoma. Hepatology 42: 1208-1236

Chan HL (2011) Significance of hepatitis B virus genotypes and mutations in the development of hepatocellular carcinoma in Asia. J Gastroenterol Hepatol 26: 8-12
Perhaps the more significant finding of the present study is that virological characteristics including $\mathrm{HBV}$ DNA levels and the distribution of $\mathrm{HBV}$ genotypes and the prevalence of precore A1896 and BCP T1762/A1764 mutants all failed to show any significant difference between cirrhotic patients with HCC and ageand sex-matched cirrhotic patients without HCC (Table 3). These findings highly suggested that all theses viral factors are not directly involved in the pathogenesis of HCC in patients with HBVrelated cirrhosis. In the previous meta-analysis, the pooled frequencies of BCP T1762T/A1764 mutant in the control groups were $46.2 \%$, significantly lower than that of $70.6 \%$ in HCC patients (Liu et al, 2009). However, it should be pointed out that the control groups consisted of asymptomatic carriers, chronic hepatitis patients and cirrhotic patients, with the pooled frequencies of BCP T1762/A1764 mutant being 28.3\%, $49.9 \%$ and $70.6 \%$, respectively (Liu et al, 2009). The frequency of BCP T1762T/ A1764 mutant in HCC patients and cirrhotic controls indeed was similar. The age and gender distribution of HCC patients and controls enroled in that meta-analysis was unknown. In this investigation, the frequencies of BCP T1762T/A1764 mutant among age- and sex-matched inactive carriers, non-cirrhotic HCC, cirrhotic patients and cirrhotic HCC were $21.6 \%, 33.3 \%$, $69.6 \%$ and $72 \%$, respectively. These results highly suggested that BCP T1762/A1764 mutant is associated with progression to cirrhosis but not directly related to HCC development. Further prospective studies are needed to ascertain whether the risk of HCC development might be different between cirrhotic patients with and without BCP T1762T/A1764 mutant. Interestingly, in a study using laser capture microdissection of hepatocytes from patients with HBV-related HCC, there is no difference in the mutation profile at BCP region between tumour and non-tumour cells (Iavarone et al, 2003). It seems likely that cirrhosis per se is a pre-malignant lesion, but whether other viral mutations (Liu et al, 2009) or host and environmental factors (Fattovich et al, 2004) might predispose the cirrhotic patients to development of HCC warrants further investigation.

In conclusion, the present study revealed that (1) BCP T1762/ A1764 mutant is an independent risk factor for progression to cirrhosis; (2) the prevalence of BCP T1762/A1764 mutant in noncirrhotic patients with HCC is low, as in inactive carriers; and (3) the prevalence of BCP T1762/A1764 mutant is high in both cirrhotic patients with HCC and cirrhotic patients without HCC. Taken together, these data highly suggest that BCP T1762/A1764 mutant is associated with progression to cirrhosis rather than HCC in chronic HBV infection.

\section{ACKNOWLEDGEMENTS}

This study was supported by grants from National Science of Council of Taiwan (NSC 99-2314-B-182-029-MY3).

\section{Conflict of interest}

Liaw YF has been involved in clinical trails or served as a global advisory board member of Roche, Bristol-Myers Squibb, GlaxoSmithKline, Novartis and Gilead Sciences. The other authors declare no conflict of interest.
Chan HL, Hui AY, Wong ML, Tse AM, Hung LC, Wong VW, Sung JJ (2004) Genotype C hepatitis B virus infection is associated with an increased risk of hepatocellular carcinoma. Gut 53: 1494-1498

Chen CH, Lee CM, Lu SN, Changchien CS, Eng HL, Huang CM, Wang JH, Hung CH, Hu TH (2005) Clinical significance of hepatitis B virus (HBV) 
genotypes and precore and core promoter mutations affecting $\mathrm{HBV}$ e antigen expression in Taiwan. J Clin Microbiol 43: 6000-6005

Chen CJ, Yang HI, Su J, Jen CL, You SL, Lu SN, Huang GT, Iloeje UH, REVEAL-HBV Study Group (2006) Risk of hepatocellular carcinoma across a biological gradient of serum hepatitis B virus DNA level. JAMA 295: $65-73$

Chu CM, Liaw YF (2005) Genotype C hepatitis B virus infection is associated with a higher risk of reactivation of hepatitis $\mathrm{B}$ and progression to cirrhosis than genotype B: a longitudinal study of hepatitis B e antigen-positive patients with normal aminotransferase levels at baseline. J Hepatol 43: 411-417

Chu CM, Chen YC, Tai DI, Liaw YF (2010) Level of Hepatitis B virus DNA in inactive carriers with persistently normal levels of alanine aminotransferase. Clin Gastroenterl Hepatol 8: 535-540

Chu CM, Yeh CT, Chiu CT, Sheen IS, Liaw YF (1996) Precore mutant of hepatitis $\mathrm{B}$ virus prevails in acute and chronic infections in an area in which hepatitis B is endemic. J Clin Microbiol 134: 1815-1818

Fang ZL, Sabin CA, Dong BQ, Ge LY, Wei SC, Chen QY, Fang KX, Yang JY, Wang XY, Harrison TJ (2008) HBV $\mathrm{A}_{1762} \mathrm{~T}, \mathrm{G}_{1764} \mathrm{~A}$ mutations are a valuable biomarker for identifying a subset of male HBsAg carriers at extremely high risk of hepatocellular carcinoma: A prospective study. Am I Gastroenterol 103: 2254-2262

Fang ZL, Yang J, Ge X, Zhuang H, Gong J, Li R, Ling R, Harrison TJ (2002) Core promoter mutations (A(1762)T and G(1764)A) and viral genotype in chronic hepatitis B and hepatocellular carcinoma in Guangxi, China. J Med Virol 68: 33-40

Fattovich G, Brollo L, Giustina G, Noventa F, Pontisso P, Alberti A, Realdi G, Ruol A (1991) Natural history and prognostic factors for chronic hepatitis type B. Gut 32: 294-298

Fattovich G, Stroffolini T, Zagni I, Nonato F (2004) Hepatocellular carcinoma in cirrhosis: incidence and risk factors. Gastroenterology 127: S35-S50

Fujie H, Moriya K, Shintani Y, Yotsuyanagi H, Iino S, Koike K (2001) Hepatitis B virus genotypes and hepatocellular carcinoma in Japan. Gastroenterology 120: 1564-1565

Iavarone M, Trabut JB, Delpuech O, Carnot F, Colombo M, Kremsdorf D, Bréchot C, Thiers V (2003) Characterization of hepatitis B virus X protein mutants in tumor and non-tumor liver cells using laser capture microdissection. J Hepatol 39: 253-261

Iloeje UH, Yang HI, Su J, Jen CL, You SL, Chen CJ, Risk evaluation of viral load elevation and associated liver disease/cancer-in HBV (the REVEALHBV) Study Group (2006) Predicting cirrhosis risk based on the level of circulating hepatitis B viral load. Gastroenterology 130: 678-686

Kao JH (2002) Hepatitis B viral genotypes: clinical relevance and molecular characteristics. J Gastroenterol Hepatol 17: 643-650

Kao JH, Chen PJ, Lai MY, Chen DS (2000) Hepatitis B genotypes correlate with clinical outcomes in patients with chronic hepatitis B. Gastroenterology 118: 554-559

Kao JH, Chen PJ, Lai MY, Chen DS (2003) Basal core promoter mutations of hepatitis $\mathrm{B}$ virus increase the risk of hepatocellular carcinoma in hepatitis B carriers. Gastroenterology 124: 327-334

Liaw YF, Chu CM (2009) Hepatitis B virus infection. Lancet 373: 582-592

Liaw YF, Tai DI, Chu CM, Chen TJ (1988) The development of cirrhosis in patients with chronic type B hepatitis: a prospective study. Hepatology 8: 493-496
Lin CL, Liao LY, Wang CS, Chen PJ, Lai MY, Chen DS, Kao JH (2005) Basal core promoter mutant of hepatitis $\mathrm{B}$ virus and progression of liver disease in hepatitis B e antigen-negative chronic hepatitis B. Liver Int 25: 564-570

Lin DY, Sheen IS, Chiu CT, Lin SM, Kuo YC, Liaw YF (1993) Ultrasonographic changes of early liver cirrhosis in chronic hepatitis B: a longitudinal study. J Clin Ultrasound 21: 303-308

Lindh M, Hannoun C, Dhillon AP, Norkans G, Horal P (1999) Core promoter mutations and genotypes in relation to viral replication and liver damage in East Asian hepatitis B virus carriers. J Infect Dis 179: 775-782

Liu CJ, Chen BF, Chen PJ, Lai MY, Huang WL, Kao JH, Chen DS (2006) Role of hepatitis B viral load and basal core promoter mutation in hepatocellular carcinoma in hepatitis B carriers. J Infect Dis 193: 1258-1265

Liu S, Zhang H, Gu C, Yin J, He Y, Xie J, Cao G (2009) Associations between hepatitis $\mathrm{B}$ virus mutations and the risk of hepatocellular carcinoma: a meta-analysis. J Natl Cancer Inst 101: 1066-1082

Orito E, Mizokami M, Sakugawa H, Michitaka K, Ishikawa K, Ichida T, Okanoue T, Yotsuyanagi H, Iino S (2001) A case-control study for clinical and molecular biological differences between hepatitis $\mathrm{B}$ viruses of genotypes B and C. Japan HBV Genotype Research Group. Hepatology 33: $218-223$

Sugauchi F, Orito E, Ichida T, Kato H, Sakugawa H, Kakumu S, Ishida T, Chutaputti A, Lai CL, Gish RG, Ueda R, Miyakawa Y, Mizokami M (2003) Frequent coinfection with hepatitis $\mathrm{B}$ virus strains of distinct genotypes detected by hybridization with type-specific probes immobilized on a solid-phase support. J Virol Methods 110: 29-35

Tai DI, Lin SM, Sheen IS, Chu CM, Lin DY, Liaw YF (2009) Long-term outcome of hepatitis B e antigen-negative hepatitis B surface antigen carriers in relation to changes of alanine aminotransferase levels over time. Hepatology 49: 1859-1867

Takahashi K, Aoyama K, Ohno N, Iwata K, Akahane Y, Baba K, Yoshizawa H, Mishiro S (1995) The precore/core promoter mutant (T1762A1764) of hepatitis B virus: clinical significance and an easy method for detection. J Gen Virol 76: 3159-3164

Tong MJ, Blatt LM, Kao JH, Cheng JT, Corey WG (2007) Basal core promoter T 1762/A1764 and precore A1896 gene mutations in hepatitis B surface antigen-positive hepatocellular carcinoma: a comparison with chronic carriers. Liver Int 27: 1356-1363

Yang HI, Yeh SH, Chen PJ, Iloeje UH, Jen CL, Su J, Wang LY, Lu SN, You SL, Chen DS, Liaw YF, Chen CJ, REVEAL-HBV Study Group (2008) Associations between hepatitis $B$ virus genotype and mutants and the risk of hepatocellular carcinoma. J Natl Cancer Inst 100: 1134-1143

Yu MW, Yeh SH, Chen PJ, Liaw YF, Lin CL, Liu CJ, Shih WL, Kao JH, Chen DS, Chen CJ (2005) Hepatitis B virus genotype and DNA level and hepatocellular carcinoma: a prospective study in men. J Natl Cancer Inst 97: $265-272$

Yuen MF, Tanaka Y, Shinkai N, Poon RT, But DY, Fong DY, Fung J, Wong DK, Yuen JC, Mizokami M, Lai CL (2008) Risk for hepatocellular carcinoma with respect to hepatitis $\mathrm{B}$ virus genotypes $\mathrm{B} / \mathrm{C}$, specific mutations of enhancer II/core promoter/precore regions and HBV DNA levels. Gut 57: 98-102

This work is published under the standard license to publish agreement. After 12 months the work will become freely available and the license terms will switch to a Creative Commons Attribution-NonCommercial-Share Alike 3.0 Unported License. 